\title{
The Patterns of Mobility and the Socio-Spatial Environments Created in and around the important multimodal nodes in a global city - A case of Navi Mumbai
}

\author{
Suhel M Makandar ${ }^{1, *}$. Saharsha A Naik ${ }^{2}$ \\ ${ }^{1}$ Amity University, Bhatan, Panvel, Maharashtra, India \\ ${ }^{2}$ Amity University, Bhatan, Panvel, Maharashtra, India.
}

\begin{abstract}
Globalization is seen as an important phenomenon shaping and reconfiguring the urbanism around the world. The urban fabric/society is directly impacted by the global network in which a city falls. For example an economic global city will have different issues than the political global city. Mumbai - Navi Mumbai is one of the cities in India which fulfils the most indicators to be a global city. The city had its own share of urban issues and the advent of globalization has led to origination of certain contemporary patterns of city development which address the past urban challenges as well as accommodate present global economy, yet it has been seen that these patterns rather address only the present conditions and the long term strategies with evolution of lifestyle and technology are uncertain. Transportation has evolved as an important aspect influencing the growth patterns of a city. This paper discusses the impacts of multimodal transport developments as a catalyst to growth of cities, its benefits and shortcomings.
\end{abstract}

\section{Introduction:}

Globalization along with global modern technologies has led urbanisation towards a completely new paradigm, yet in popular literature globalization is portrayed as a very recent phenomenon, but the fact is that we have already been living in a truly global world for ages [1].

The current trend of globalization is an offshoot of the tremendous power of information and communication technologies that decentralized the economy from one particular city to a number of cities which come in network of global loop [2]. It can be argued upon that, it is not only the important economic centres(cities), which form a network of the global cities; there are the networks of political global cities, religious global cities, global cities of importance for activistism. The urban fabric and the society are directly impacted by the global network in which a city falls. For example an economic global city will exhibit different issues then the political global city.

Many of the current global cities were a part of the influential cities in the past and when the current wave of globalization based on the ICT revolution swept the world, it created service based economy and this introduced a drastic change in the functioning of historic influential cities that were - say at one time manufacturing and industrial towns. Today the industries and the manufacturing units have largely shut down or relocated and the urbanism made way to cater the service based economy [3].

\footnotetext{
*Corresponding author: smmakandar@mum.amity.edu
}

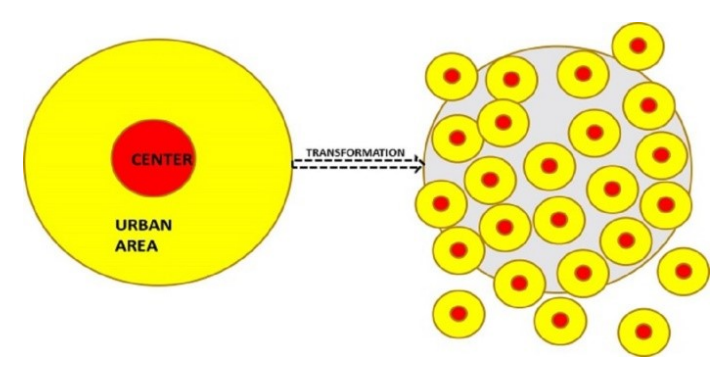

Figure 1 Decentralisation of urban Centre as envisaged due to Information and Communication Technology.

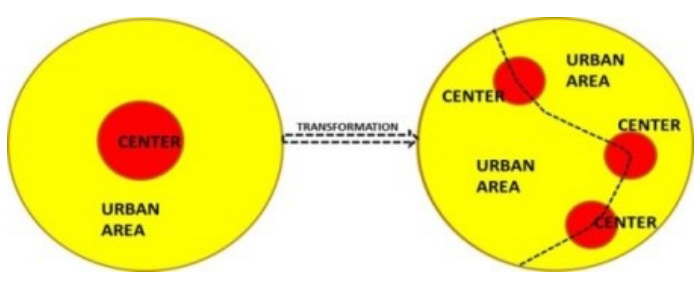

Figure 2 Recentralisation of the traditional urban center into a network of nodes which form a new centre

Bases upon the transition from manufacturing to service based urbanism, the changing fabric of the urban area was very pronounced in the urban centre. The electronic realm helped in decentralizing the centre and it was further envisioned that the electronic media and ICT would decentralize the urban centre to such an extent that the urban character would be lost 'as seen in Figure1. However this doesn't happen and there is a reverse action seen, the centre gets decentralized into 
various centres of special activities, eventually forming a network of nodes within the city 'as seen in figure 2 . These networks of nodes connect, thrive and get accentuated through lines of transportation which forms a vital link. The hierarchy of transportation varies in these nodes from regional level to local ward level and hence they eventually start taking up a form of multimodal hub, weather the city designers make provision for it or not.

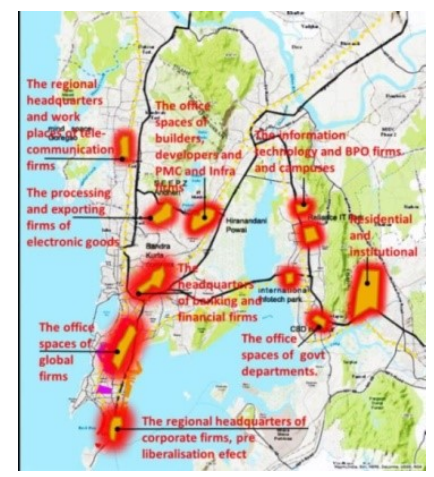

Figure 3 Mumbai - Navi Mumbai and its important activity nodes

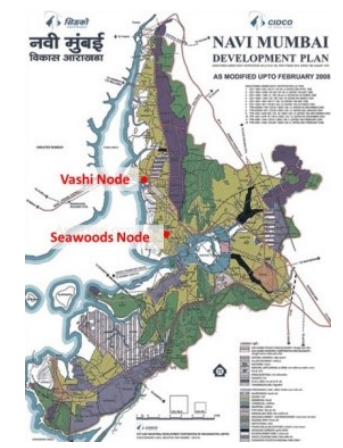

Figure 4 Navi Mumbai City development plan showing the two nodes of study area

In the further course of paper intentionally designed multi modal hub shall be investigated upon to ascertain the pattern and layers of mobility and the impact it creates on the socio-spatial aspect as well as urban design.

\section{Method and Material:}

Methodology: - The method adopted for research is through spatial map analysis. The attributes for evaluation are taken based upon the findings from review of various relevant research papers. The spatial integration and system of patterns created for the following elements are studied in this research paper:-

- Urban Centre \& Node

- Patterns of connectivity

- Developments in and around the Multimodal node

- Typology of development of node

- Impact of Node on the surrounding urbanism

- User group interaction
Material:- The materials for study are primary visual survey, satellite imagery and mapping, research studies on impact of mobility patterns on the city and concept of 'urban Centre'.

\section{Discussions:}

Mumbai has always been an important destination on the network of global influential cities, the growth prospects and economic opportunities have led to the tremendous physical growth of cities into a system of sister cities. Today the Mumbai Metropolitan Region(MMR) comprises of multiple municipal areas such as Navi Mumbai, Panvel, Vasai Virar, Kalyan Dombivali, Mira Bhayandar, where all these cities together function as different organs of one large city i.e. Mumbai. All these organs function in synchronization as they are connected by common veins which are the Suburban railway network [4].

Out of all these cities Navi Mumbai is a planned city which was foreseen as an attempt to decongest the Island city of Mumbai in the early 1970's [5]. It was planned with consideration for the Local Suburban Rail Network as the backbone connecting the various nodes of Navi Mumbai to the Island city. Hence the Railway stations gained a pivotal role spatially as well as functionally in all the nodes. Today these railway stations have gained a central function as the urban nodes have got self-sustainable and depend lesser for day to day activities on the island city [6].

The railway stations achieving a central function was envisaged well in advance by the planners of Navi Mumbai and hence the railway stations were proposed to be developed as a multifunctional node having a combination of multi-layered transportation as well as economic activities [7]. The Nodes of Vashi and Seawoods are an example for development of multifunctional nodes having different activity juxtaposing with transportation in each case.

\subsection{Vashi Node}

This node was the first of the settlements to blossom outside the island city in Navi-Mumbai, the Vashi railway station is developed as a combination of a transportation node as well as an economic node in the form Railway Station at the Ground floor level and International InfoTech Park building on the floors above. This International InfoTech park has provision for office establishments thus resulting in bringing a certain amount of self-dependency with reference to employment in the newer nodes.[8] The Developments around the Vashi railway station comprises of commercial use catering to a wide usage from office spaces to retail and large scale shopping malls. Also there are large scale parking lots abutting the railway station. 


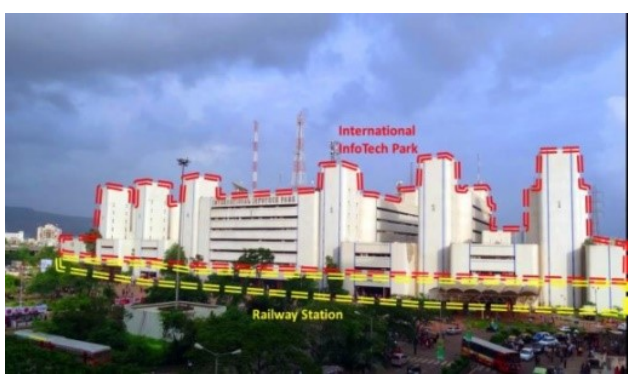

Figure 5 Vashi Multimodal Railway station

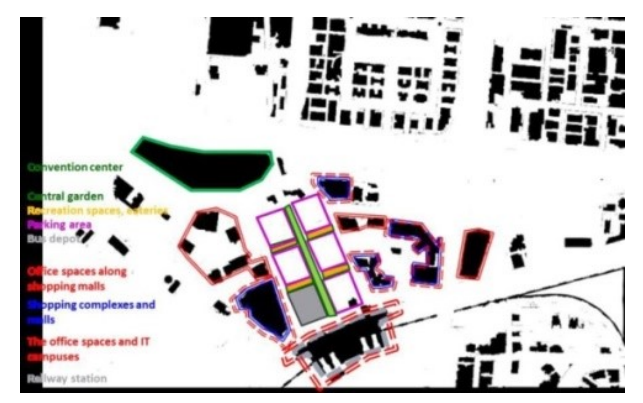

Figure 6 Figure-ground map Vashi railway station precinct

Certain challenges which are an outcome of the Multimodal Node typology in Vashi are as follows:-

\subsubsection{Challenges in Vashi Node}

- Commercial developments in the entire sector where Multimodal hub is located makes the entire sector deserted space post $9 \mathrm{pm}$.

- Larger footprints of buildings and developments in the surrounding result in lack of human-built environment interactional experience.

- Lack of urban design elements like visual character, public engaging activities around the node

- As this multimodal hub attracts huge footfall the above issues are critical to the public comfort. [9]

\subsection{Seawoods Node}

Seawoods gathered its fame and recognition for the flagship NRI housing scheme implemented by City and Industrial Development Corporation (CIDCO). The Seawoods railway station is designed as a multimodal transport node where there is Railway station at the ground floor and Grand Central Complex on the floors above. The Grand central comprises of shopping mall, office spaces, recreational spaces and multilevel parking on floors above. The grand central complex now acts as a strong magnet for retail, entertainment and economic activities in Seawoods locality [10]. The developments in surrounding of Seawoods Railway station comprises of mixed use buildings which are a combination of upscale apartments as well as retail and commercial spaces.

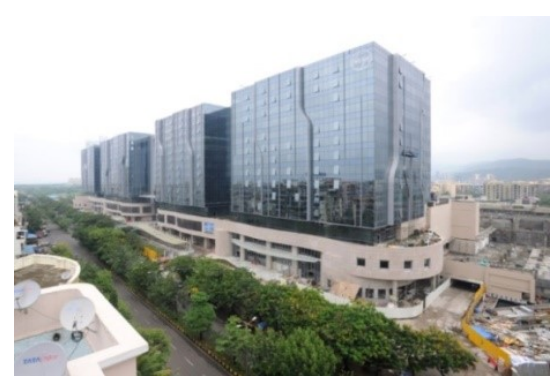

Figure 7 Grand Central Complex(Seawoods Node)

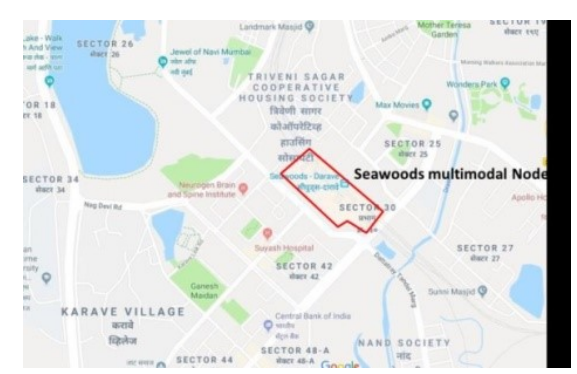

Figure 8 Seawoods Node Map

It can be seen from the example of Vashi and Seawoods nodes that the idea of a multimodal transport node has helped in the development of the city by garnering pace and self-sustenance (from island city) to the newly developing localities. This strategy is indeed helpful when viewed at a larger City development scale as a multi modal hub comprising of commercial and office spaces along the railway station helps in reducing an arm of modal split for people using public transport to reach these spaces. But when viewed at the individual node level, there are certain challenges which are an outcome of this typology of development.[11]

While the Multimodal hub becomes the primary node for transportation and economic/retail activity it attracts large traffic, especially during the peak hours. The public transport (referred to bus services here) in these newer areas are rather less in frequency and do not cater to larger mass volume routes. The commuters also rather do not prefer local buses due to the bad state of the buses, unpredictable waiting time, longer period of time taken to cover the same distance as compared to personal car, inconvenience in summer and monsoon seasons. [12] Hence in these newer areas personal vehicle usage has drastically increased especially for the Intra node commuting, thus it is evident that the Multimodal node becomes a magnet for vehicles especially during the peak hours. Certain challenges which are an outcome of the Multimodal Node typology in Seawoods node are as follows:-

\subsubsection{Challenges in Seawoods Node}

- Here the issues are related to the connectivity of surrounding localities and congestion around the Multimodal node.

- It is seen that there is a vibrant public realm and enclosure but the congestion leads to deterioration in public experience. 


\section{Alternative approaches:}

In planned nodes, it is essential that there is a constant evaluation of the previous planned developments. The stereotype model should be constantly moulded in order to enhance the urban experience and quality of lifestyle. The following approach for newer developing nodes in Navi Mumbai can be adopted:

- The Railway stations which were envisioned as multimodal nodes now are acquiring the status of Major Node itself and thus in the newer areas there should be strategies for counterbalance through a network of micro-nodes.

- The technology of light mass transit like mono rail, PRT, Trams, are becoming affordable and sophisticated(requiring lesser road footprint) as technologies are advancing and thus becoming attractive for municipal corporations, the same shall be employed in the newer areas and recently developed areas.

- The option for connectivity shall be established taking into account the Inter-nodal (within city amongst suburbs) and Intra-nodal (within the suburb) transport and commutation patterns in order to understand the overlay and confluence points.

- By decongesting the Central node i.e. the multimodal hub from vehicles, the street space can be reclaimed for public realm, as the nodes attract large footfall it is essential to create a vibrant public realm using urban design elements like streetscape, furniture and breathing/halting spaces.

- The areas surrounding the Multimodal node shall have a mixed land use in order to avoid the chances of creating post working hour ghost spaces.

- The building blocks should have an ideal perimeter of $400 \mathrm{~m}$ to $600 \mathrm{~m}$ (reference to Barcelona blocks) and the street edge should be vibrant and visually permeable.

- In case of the metro stations/monorail projects being implemented the buildings surrounding the metro station shall have customised regulations in order to make most by establishing direct connectivity to the station and also enhance the visual realm.

All the above factors are to work in tandem and not a piece meal manner for a better socio spatial integration and enhanced urban experience in future.

\section{Acknowledgements:}

I am grateful to Prof. A. D. Shirodkar (Amity University Mumbai) for constant encouragement in taking up research work. I am thankful to Amity University Mumbai for their motivation to build up, compile and complete this research work. I am indebted to alma mater SPA Bhopal, SSSMS COA Sholapur, as well as Taranum Makandar.
1. Sassen, Saskia. Place and Production in the World Economy. Cities in a World Economy. New york : Sage Publishing, (1994)

2. From Global Cities to Globalised Urbanism. Brenner, Neil and Keil, Roger. (2014)

3. Bishop, Ryan, Phillips, John and Yeo, Wei Wei. Perpetuating Cities: Excepting Globalisation and the Southeast Asia Supplement. Post Colonial Urbanism: Southeastern Asian Cities and Global Processes. (2013)

4. Prajakta, R Rail network may reach Raigad district. Hindustan Times 22jan (2017)

5, NMMC history website. https://www.nmmc.gov.in/history (2019)

6. PWC, Revenue Maximizing Study Report for MRVC. (2014)

7. Livemint Report. https://www.livemint.com/companies/news /l-t-realty-gets-strong-demand-for-500flats-on-offer-in-navi-mumbai-project1557905551843.html (2019)

8. Amit C, Chattopadhyay RN. Satellite Towns in Neo-Metropolitan Development in India. Springer (2019).

9. Pranab JB.

https://www.hindustantimes.com/cities/me ss-cleared-from-vashi-railway-stationpremises/storya93z6t4bTiYf5NVinZXvsK.html (2019)

10. Moneycontrol. https://www.moneycontrol.com/news/busi ness/real-estate/lt-realty-eyes-rs-3200-crrevenues-from-navi-mumbai-project3974001.html (2019)

11. Sandeep K. India Retailing, Driving the Change

https://www.indiaretailing.com/2019/09/2 $0 /$ shopping-centre/driving-the-changemalls-use-technology-for-smart-parkingsolutions/ (2019)

12. Karthik R. Navi Mumbai, Retrofitting a Planned City. The City Fix blog, (2010)

\section{References}

